\title{
Antimalarial treatment by health care providers in Port Harcourt, Nigeria
}

\author{
Omotavo O Ebong*, Erne O Asuguo, Chijioke A Nwauche, lyeopu M Siminialayi, Ijeoma H Ogbuehi, \\ Mercy F Ajienka \\ From Challenges in malaria research \\ Basel, Switzerland. 10-12 October 2012
}

\section{Background}

In Nigeria, malaria accounts for $60 \%$ of outpatient visits, $30 \%$ hospitalization, and is estimated to be responsible for about $11 \%$ of overall maternal mortality, $25 \%$ of infant mortality, and $30 \%$ of under-five mortality [1]. The disease is particularly virulent among pregnant women and the under-five years of age, due to their low levels of immunity. It impedes economic growth and keeps households in poverty. Lack of access to diagnostic testing before treatment is one of the weaknesses in the management of malaria in Nigeria [2]. This study examines the treatment practice for malaria among health care providers (HCPs) in Port Harcourt.

\section{Materials and methods}

This was a cross-sectional study among HCPs, and data collection was by use of pre-validated questionnaires and in-depth interviews. The data was analyzed using SPSS Version 17.

\section{Results}

A total of 273 HCPs (doctors, nurses, pharmacists, community health workers (CHWs) and private medicine vendors (PMVs)) were randomly selected from health care facilities in Port Harcourt. Of the HCPs, $100 \%$ of doctors \& pharmacists; $89.6 \%$ nurses; 33.3\% PMVs; and $25 \%$ CHWs are aware of the World Health Organizations (WHO) treatment guidelines. The ACTs (69.2\%) and sulphadoxine / pyrimethamine $(7.7 \%)$ were the most prescribed drugs for uncomplicated malaria in children. Other drugs prescribed were: Chloroquine, Quinine, and Artesunate (group 1), 5.1\%; and Pyrimethamine and Paracetamol (group 2), 2.6\%. For severe malaria in children, Quinine (46.2\%), the ACTs (20.5\%) and intravenous artemether $(12.8 \%)$ were mostly used. The other drugs prescribed were those in groups 1 and 2 above. For uncomplicated malaria in adults, the ACTs (66.7\%) and sulphadoxine /pyrimethamine (17.9\%) were most prescribed in addition to the other drugs in groups 1 and 2. For severe malaria in adults, Quinine (46.2\%), the ACTs $(20.5 \%)$ and intravenous artemether $(12.8 \%)$ were mostly prescribed. For pregnant women, sulphadoxine /pyrimethamine (76.9\%), the ACTs (10.3\%), Artesunate (7.7\%) and Quinine (5.1\%) were mostly prescribed. Regarding adherence to WHO treatment guidelines, only $44.3 \%$ of HCPs [doctors, 52.1\%; Nurses, 23.1\%; Pharmacists, 11.6\%; PMVs, 7.4\% and CHWs, 6.0\%] used diagnostic testing before treatment. Proximity to a good laboratory, laboratory costs, and availability of diagnostic tools are major factors that influence HCPs' decisions in carrying out proper diagnosis before treatment.

\section{Conclusion}

This study shows that, while the ACTs are widely used for the treatment of malaria in Nigeria, a larger proportion of the treatment is not based on diagnostic evaluation. Many HCPs recognize that diagnostic testing should precede treatment, but do not have the required facilities for it.

Published: 15 October 2012

\section{References}

1. Roll Back Malaria Partnership, WHO: Focus on Nigeria: Progress \& Impact Series. Country Reports 2012, 4:58.

2. National Malaria Control Programme Federal Ministry of Health, Nigeria: Implementation Guide for Parasite-Based Diagnosis of Malaria. 2011 [http://nmcpnigeria.org/f/case-management/IMPLEMENTATION\%20GUIDE\% 20FOR\%20RDT\%20DEPLOYMENT\%20MAR_2011.pdf], 19. 
doi:10.1186/1475-2875-11-S1-P28

Cite this article as: Ebong et al:: Antimalarial treatment by health care

providers in Port Harcourt, Nigeria. Malaria Journal 2012 11(Suppl 1):P28.

Submit your next manuscript to BioMed Central and take full advantage of:

- Convenient online submission

- Thorough peer review

- No space constraints or color figure charges

- Immediate publication on acceptance

- Inclusion in PubMed, CAS, Scopus and Google Scholar

- Research which is freely available for redistribution

Submit your manuscript at 